\title{
"Aproximaciones a la historia de la lectura en Honduras: Lecturas en soledad y lecturas en público en el período liberal de finales del siglo XIX y principios del XX"
}

Dr. Jorge Alberto Amaya Banegas

UPNFM jorgealbertoamaya@gmail.com

\section{Tipos o modalidades de lecturas en Honduras: Lecturas en soledad y lecturas públicas}

El presente artículo pretende retomar la tipología expuesta por Roger Chartier entre "lecturas en soledad" y "lecturas en público" para analizar la manera en que los lectores hondureños de finales del siglo XIX y comienzos del XX aprehendieron, manejaron y se apropiaron de los significados o textos puestos en los libros. Es decir, intentaremos trazar cómo se manifestaron este tipo de lecturas en el país, cuáles eran las prácticas y las representaciones que resultaban de dichas lecturas, especialmente por parte de algunos miembros de la "clase letrada", así como por parte de algunas familias de la clase alta de la ciudad de Tegucigalpa de aquellos años.

En primer lugar, hay que recapitular que Chartier expresa que las "lecturas en soledad" son lecturas del "retiro", que se hacen en secreto, en el aislamiento. Esta forma de lectura ha sido quizás por antonomasia la más "natural" y habitual, lo cual no significa que sea la lectura más extendida en los últimos siglos. 


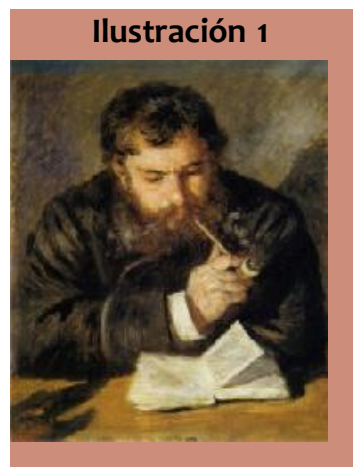

La lectura en soledad se caracteriza porque se realiza en el retiro, en silencio. (Cuadro El lector).

Por su parte, las “lecturas en público”, se generalizaron en Europa y luego en América Latina-entre los siglos XVII y XIX, y se expresaron desde las diligencias hasta las tabernas, desde los salones hasta las academias, de las tertulias a la reunión doméstica, y a diferencia de la "lectura en soledad", eran lecturas en alta voz realizadas por quienes sabían leer tanto a lectores/oyentes alfabetos como analfabetos. De esta forma, leer en voz alta se constituyó en un gesto normal y hasta esperado en esa época. En suma, la lectura no ha sido por tanto una práctica de lo íntimo o de lo privado; también es expresión del vínculo social.

Lectura en público, modalidad que se puso de moda a partir de la llustración Francesa, y que luego pasa a América Latina entre los siglos XIX y XX. (Cuadro: "Lectura de Moliere", por Jean Francois Detroit).

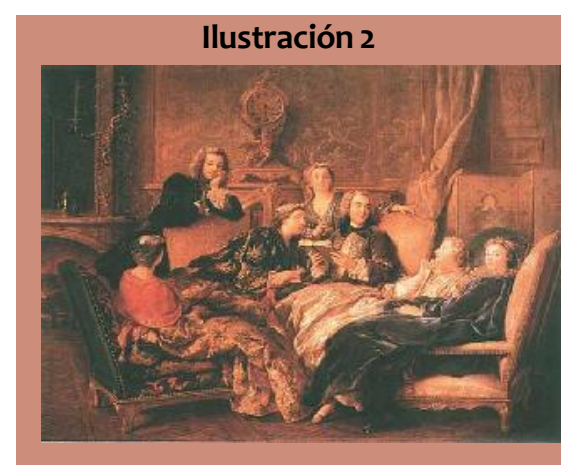

En concreto, analizaremos en el caso de las "lecturas en soledad" las prácticas de lectura realizadas por los dos escritores más importantes de la época: el poeta Juan Ramón Molina y el cuentista y también poeta Froylán Turcios, y con respecto a las "lecturas en público", abordaremos las lecturas que realizaban en su hogar la familia del escritor Marco Antonio "Toño" Rosa. 


\section{A) Lecturas en soledad: Juan Ramón Molina y Froylán Turcios.}

Juan Ramón Molina' ha sido considerado por gran parte de la crítica literaria hondureña como el más egregio poeta de la historia del país. Existen razones de peso para ello, pues a pesar de que su obra no tuvo la fama y resonancia de Rubén Darío, ciertamente su producción ha sido elogiada por respetables escritores y creadores de las letras hispanoamericanas, como Emilio Castelar, José Santos Chocano, Rafael Arévalo Martínez, José María Vargas Vila, Enrique González Martínez, Max Henríquez Ureña, Miguel Ángel Asturias, Enrique Anderson Imbert y hasta del mismo Darío.

La obra de Molina fue publicada de manera póstuma por su íntimo amigo, Froylán Turcios, con el título de Tierras, mares y cielos², como cumplimiento de una promesa que éste hiciera a Molina antes de su muerte.

Juan Ramón Molina, máximo exponente de la poesía modernista en Honduras. (Archivo del autor).

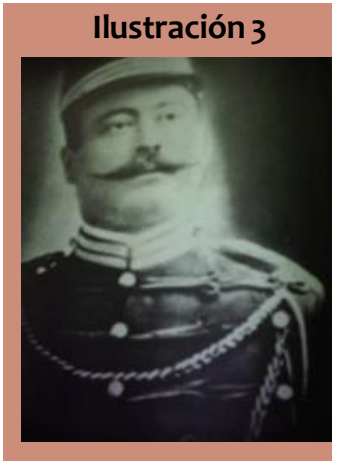

\footnotetext{
${ }^{1}$ Juan Ramón Molina nació en Tegucigalpa en 1875 y murió en San Salvador en 1908. Es considerado el poeta modernista más importante de Centroamérica después de Rubén Darío. Escribió prosa y verso, además de ejercer el periodismo en Honduras, Guatemala y El Salvador. Viajó por Suramérica y Europa, sin embargo, su vida un tanto díscola le dio fama de "poeta maldito". Su obra fue recogida de manera póstuma por su amigo Froylán Turcios bajo el sugestivo título de "Tierras, mares y cielos" en 1911. Miguel Ángel Asturias lo puso a la altura del poeta insigne del Modernismo, Rubén Darío: Cfr. Asturias, Miguel Ángel, “Juan Ramón Molina, poeta gemelo de Rubén”, En: Antología de Juan Ramón Molina, San Salvador, Ministerio de Educación, 1959.

${ }^{2}$ Molina, Juan Ramón, Tierras, mares y cielos, Tegucigalpa, 1911. Existen abundantes ediciones de esta obra, publicadas en varios países de Latinoamérica. Nosotros seguiremos de ahora en adelante la edición prologada y anotada por el hondureño Julio Escoto: Juan Ramón Molina. Tierras, mares y cielos, Selección, introducción y notas de Julio Escoto, San José de Costa Rica, Editorial Universitaria Centroamericana (EDUCA), Colección Aula, $1^{\text {a }}$ edición, 1977.
} 
A pesar de la vida un tanto díscola y bohemia de Molina, expuesta en un sinfín de anécdotas y leyendas en algunas biografías y en la tradición oral hondureña, lo cierto es que las fuentes y estudios más serios acerca del autor dan cuenta de que Molina fue un gran lector, que se empapó no solamente de la literatura más reciente de la época, sino que también estudió a los clásicos y a las principales corrientes literarias de la Modernidad.

En efecto, tanto él como Turcios, se consideraron herederos del Positivismo impuesto por la Reforma Liberal, pero ciertamente, lograron superar esa filosofía y se podría decir que parte de la obra de ellos incursionó en otras fuentes que de alguna manera representaban una reacción contra el positivismo.

Hay que señalar que el positivismo latinoamericano -a diferencia de Europa-, tuvo sus propios rasgos, y a pesar que en un primer momento fustigó a las fuerzas más conservadoras de la sociedad y que proponía la instauración de un orden social nuevo, basado en la ciencia, el trabajo y el progreso, ciertamente con el tiempo se convirtieron en defensores del statu quo. De este modo, hacia finales del siglo XIX, nuevas exigencias teóricas, unidas a nuevos movimientos sociales, empezaron a criticar la ingenua cientificidad de los positivistas y una conciencia intelectual distinta apareció en el horizonte cultural latinoamericano. Fue la gran reacción antipositivista, que en algunos países se presentó como depositaria y portadora de las concepciones humanistas universales; de ahí el renovado interés por los griegos y latinos, así como por las nuevas corrientes filosóficas, estéticas y de pensamiento social que despuntaban en Europa continental. Así, Nietzsche, Schopenhauer y el mismo Marx son los autores que empiezan a seguir varios intelectuales latinoamericanos ${ }^{3}$.

En Honduras, si hablamos con propiedad, no hubo reacción antipositivista como tal, sin embargo, las ideas y los nuevas

\footnotetext{
${ }^{3}$ Castillo, Roberto, Filosofía y pensamiento hondureño, Tegucigalpa, Editorial Universitaria, Colección Docencia, № 72, $1^{\mathrm{a}}$ edición, 2000, pp. 20-21.
} 
corrientes intelectuales también comenzaron a aflorar en la generación literaria de Molina y de Turcios. De esta forma, en Centroamérica, fueron los poetas modernistas -con Rubén Darío a la cabeza- quienes de alguna forma reaccionaron contra el positivismo, y contribuyeron de esa manera a crear una nueva conciencia humanística.

En nuestro caso, vale añadir que Molina había hecho una impresionante y atenta lectura de los grandes pensadores especulativos europeos como Nietzsche y Schopenhauer, al igual que de los clásicos como Platón, Aristóteles, Descartes, Hobbes, Kant y Schiller, para solo mencionar algunos. Su poesía trata de los grandes temas de la humanidad, como la muerte, el universo y la libertad, temas más cercanos a la mentalidad postpositivista 5 .

En todo caso, más allá de esos autores más bien contemporáneos para la época de Molina, otras fuentes indican que leyó con profusión buena parte de la literatura universal de todos los tiempos. Julio Escoto, en su excelente edición de la obra de Molina, cita un estudio del estadounidense William Chaney de 1921, en donde presenta una extensa y pormenorizada lista de las lecturas que había hecho Molina a lo largo de su corta vida ${ }^{6}$.

\footnotetext{
${ }^{4}$ Véase: Molina, Juan Ramón, “Nietzsche”, En: Molina, Juan Ramón, Prosas, Tegucigalpa, Secretaría de Cultura y Turismo, Colección Biblioteca Básica de Cultura Hondureña, N², 2ª edición, 1984, pp. 268-273.

5 Castillo, Roberto, Filosofía y pensamiento hondureño... Op. Cit., p. 22.

${ }^{6}$ Chaney señalaba que Molina había leído y citado a autores representativos de todas las épocas; por razones de espacio, referiremos solamente una parte de ellos: $a$ ) autores norteamericanos: Edgar Allan Poe y Roosevelt; $\boldsymbol{b}$ ) autores franceses: Balzac, Baudelaire, Bossuet, Chateaubriand, Dantón, Descartes, Flaubert, Víctor Hugo, Lamartine, Mallarmé, Marat, Maupassant, Michelet, Musset, Moliere, Napoleón, Nerval, Renán, Richelieu, Rousseau, Taine, Tocqueville, Verlaine, Voltaire, Zolá; c) autores alemanes: Bauer, Feuerbach, Goethe, Heine, Hegel, Kant, Marx, Metternich, Nietzsche, Nordau, Schiller, Schopenhauer; d) autores ingleses: Bacon, Byron, Carlyle, Darwin, Faraday, Hobbes, Huxley, Macaulay, Milton, Newton, Shakespeare; e) autores italianos: Bocaccio, Campanela, Casanova, Copérnico, Dante Alighieri, Fra Angélico, Galileo, Maquiavelo, Miguel Ángel; f) autores belgas: Maeterlinck; g) autores de la Grecia clásica: Aristóteles, Demóstenes, Homero, Pericles, Platón, Sócrates, Sófocles, Tales de Mileto; $\boldsymbol{h}$ ) autores romanos: Cicerón, Horacio, Lucrecio, Marco Aurelio, Petronio, Plinio, Séneca, Virgilio; i) autores egipcios: Ptolomeo; $j$ ) autores orientales: Confucio, Ciro, Mahoma; k) autores españoles: Campoamor, Castelar, Cervantes, Hernán Cortés, Echegaray, Espronceda, Fray Luis de León, Menéndez y Pelayo, Núñez de Arce, Pérez Galdós, Quevedo, el Marqués de Santillana, Lope de Vega, Juan Valera y l) autores latinoamericanos: Manuel
} 
Escoto añade que Molina desde joven reveló una excepcional e incontrolable voracidad por la lectura, por medio de la cual escudriñó todos los mitos, literaturas y filosofías imaginables: desde los clásicos hasta los modernos, desde los nihilistas hasta los teólogos, desde los esotéricos hasta autores superficiales. Así, desde sus años de estudio en Guatemala, adonde acudió en 1888 para proseguir sus estudios secundarios, su tradicional oficio era “[... ] permanecer en cama, más allá del mediodía solar, devorando volumen tras volumen de Hugo o Esquilo, de Zola o de Homero, ya de Byron, Shakespeare, de Campoamor, Rimbaud o San Agustín"7.

El mismo Molina da cuenta en su obra poética de su insaciable avidez por la literatura, especialmente en su famoso poema "Autobiografía", en donde confiesa que:

He abrevado mis ansias de sapiencia

en toda fuente venenosa y pura,

en los amargos pozos de la ciencia

y en el raudal de la literatura ${ }^{8}$.

De este modo, Molina reconoce que no solamente lee a los autores líricos, narradores o prosistas, sino también a científicos y hasta autores profanos. Enrique Anderson Imbert, uno de los críticos más famosos de su obra, señala que Molina “[... ] Leyó mucho -literatura, filosofía, aun ciencias- y su visión de la vida fue compleja. Al escribir en prosa se esforzaba en lograr un estilo pulcro y elegante, por muy sórdida que fuera la realidad que describiera"9. Desde luego, al igual que otros escritores positivistas y también modernistas, Molina

Acuña, Manuel Batres Montúfar, José Montúfar, José Santos Chocano, Rubén Darío, Manuel Diéguez, Julio Flores, Jorge Isaac, Antonio Batres Jáuregui, Juan Montalvo, Román Mayorga Rivas, José Asunción Silva, Ramón Verea y Guillermo Valencia entre otros. Cfr. Molina, Juan Ramón, Tierras mares y cielos, Selección, introducción y notas de Julio Escoto... Op. Cit., pp. 9-10. En adelante, citaremos esta obra como: TMC, edición de Julio Escoto.

7 TMC, edición de Julio Escoto, p. 10.

8 Ibíd., p. 53.

9 Véase: Anderson Imbert, Enrique, Historia de la literatura Hispanoamericana: la colonia. Cien años de república, México DF, Fondo de Cultura Económica (FCE), Colección Breviarios, $\mathrm{N}^{\circ} 89$, Tomo I, $8^{\mathrm{a}}$ reimpresión, 1993, p. 409. El subrayado es nuestro. 
estuvo interesado en lecturas científicas, muy en boga en el siglo $\mathrm{XIX}$, especialmente de los autores evolucionistas europeos, que marcaron a buena parte de la generación de escritores latinoamericanos de aquel entonces y que con los años escribieron una abundante prosa marcada por las teorías eugenésicas que buscaban el "mejoramiento racial" de la sociedad latinoamericana a través de la inmigración blanca. Así, Escoto cita a J. Cruz Sologaistóa, amigo del poeta, quien comentó que Molina "[... ] Era un evolucionista seguidor de Darwin y Lammark. El transformismo le merecía una creencia incondicional: la selección era para su espíritu de triunfador una razón de vida"10.

Estas ideas le llevaron en algún momento a criticar la composición racial y social del país, y en uno de sus artículos, Molina se lamentaba de la "exuberante" mezcla racial del hondureño, lo cual le llevó a afirmar que "[...] nosotros [los hondureños] no tenemos una civilización verdadera, sin duda por nuestras condiciones étnicas"'. Esta actitud crítica ante la composición cultural de América Latina fue claramente manifiesta en los autores del Modernismo, quienes se volcaron abiertamente a las fuentes europeas y orientales, retomando como motivos de inspiración temas provenientes de la Antigüedad clásica, oriental y de los simbolistas franceses y desdeñando en parte las temáticas latinoamericanas y del pasado prehispánico. El mismo Rubén Darío sentía una leve perturbación por su origen mestizo, y algunos amigos, durante su estadía en España, cuando trataban de mortificarlo, le llamaban socarronamente "mulato", pues sabían que se irritaba cuando le llamaban asín ${ }^{12}$. De hecho, en las palabras liminares de su obra Prosas profanas, se interroga turbadamente lo siguiente: "[...] Hay en mi sangre alguna gota de África, o de indio chorotega o nagrandano? Pudiera ser, a despecho de mis manos de marqués; más he aquí que veréis en mis versos princesas, reyes, cosas imperiales, visiones de

\footnotetext{
${ }^{10}$ TMC, edición de Julio Escoto, pp. 11-12.

${ }^{11}$ Citado en: Oquelí, Ramón, Los hondureños y las ideas, Tegucigalpa, Editorial Universitaria, Colección Cuadernos Universitarios, $\mathrm{N}^{\circ}$ 46, $1^{\mathrm{a}}$ edición, 1985, p 26.

12 Véase: Baquero, Gastón, Indios, blancos y negros en el caldero de América, Madrid, Ediciones de Cultura Hispánica, 1991.
} 
países lejanos o imposibles: ¡Qué queréis!, yo detesto la vida y el tiempo en que me tocó nacer..."13.

Por otra parte, a pesar de las amplias lecturas de Molina, hay que señalar que como autor adscrito al Modernismo, sus lecturas preferidas fueron sin duda las de Verlaine, Rimbaud, Mallarmé, Baudelaire, y más lejos Byron, Musset y Víctor Hugo ${ }^{14}$; en cuanto a la filosofía, un autor que signó la carrera literaria de Molina fue Nietzsche, del cual comentó tras su muerte que "[... ] en lo futuro, cuando se mida la magnitud de su arte, -será considerado- como uno de esos intelectuales extraordinarios que vienen a trazar un nuevo signo en el zodiaco del pensamiento humano" ${ }^{15}$. De América Latina, admiraba sobre todo al ecuatoriano Juan Montalvo, de quien dijo que era "el más grande hombre de la América Latina, y el que más gallardamente ha manejado el habla de Castilla"; así como a su compatriota Froylán Turcios y por supuesto a Rubén Darío, a quien conoció a temprana edad en Guatemala y luego trabó amistad en el viaje a la "Conferencia Panamericana de Brasil"; Molina, admirador de la obra de Darío, le dedicó un tríptico en el que le manifestaba que: "Amo tu clara gloria como si fuera mía"16. Darío, en su poema "Al partir Mayorga Rivas", expresa por su lado el cariño que sentía tanto por Mayorga Rivas como por Molina, anotando que:

Román: ya te vas al pensil de Centro América, al edén que yo, desde aquí, del Brasil, Contemplo cual perdido bien.

Te llevas de mi corazón un gran pedazo. Es la verdad.

\section{¿Qué haría yo sin Juan Ramón,}

parte de nuestra trinidad? ${ }^{17}$.

\footnotetext{
${ }^{13}$ Consúltese: Darío, Rubén, Prosas profanas, Prólogo de Antonio Gamoneda, Madrid, Alianza Editorial, Biblioteca Conmemorativa del 30 Aniversario de Alianza Editorial, 1998, p. 25.

${ }^{14}$ TMC, edición de Julio Escoto, p. 25.

${ }^{15}$ Molina, Juan Ramón, Prosas... Op. Cit., p. 267.

${ }^{16}$ TMC, edición de Julio Escoto, p. 157.

17 Véase: Darío, Rubén, “Al partir Mayorga Rivas”, En: Darío, Rubén, Poesías completas, Edición de Alfonso Méndez Plancarte, Madrid, Aguilar, 1975, pp. 1013-1014.
} 
Por otro lado, ya en su práctica de lectura, Molina se reveló a sí mismo como un "lector en soledad". En efecto, en su artículo "La tristeza del libro", establece una relación de amor-odio con el libro y las lecturas, en donde confiesa sus pasiones por la lectura, pero a la vez, la melancolía producida por algunas lecturas. En el artículo referido, hace un repaso general de la historia del libro, y manifiesta que:

Ni los griegos, tan dialécticos y gárrulos... ni los romanos... ni los hombres de la Edad Media conocieron la tristeza del libro, la melancolía de las enormes lecturas... Encerrados los conocimientos humanos en las bibliotecas de Atenas, Roma, Pérgamo y Alejandría, y en los herméticos conventos de la época feudal, a pocos hombres les era dado abrevarse en las sagradas fuentes de las ciencias y las letras. Las copias de las obras originales eran escasísimas, de tal modo que la difusión de su contenido nunca llegaba a las masas populares ${ }^{18}$.

Como se ve, Molina concibe la lectura como transmisora de estados de ánimo, que puede provocar tristeza y melancolía en espíritus sensibles como el de los poetas. Más adelante, Molina resalta el impacto de las lecturas a partir de la invención de la imprenta, que conllevó la ampliación de las lecturas por todo el mundo a lo largo de los siglos. Así, agrega que la extensa difusión de las lecturas sobre todo las lecturas vacías y superficiales- provocaban enviciamiento al mismo grado que las drogas y el alcohol:

[... con la invención de la imprenta, el libro se multiplicó con la facilidad de los panes y los peces del milagro. Millares de millones de volúmenes han sido, desde entonces, arrojados a la circulación, de tal modo que el libro se ha puesto al alcance de todo el mundo. La influencia depresiva que ha alcanzado sobre el alma moderna... es de todo innegable. En la tristeza ambiente de los últimos tiempos tiene tanta parte como el alcohol y el tabaco, porque en la forma que hoy se gusta, es... un verdadero

${ }^{18}$ TMC, edición de Julio Escoto, pp. 179-180. 
excitante cerebral, origen de profundas neurastenias. En tiempos mejores fue una especie de sedante, una bebida espiritual aromática... Hoy, -con raras excepciones- no lo es. Porque la ciencia y la literatura adolecen -de algunos años acáde [buenas] ideas... De este modo el libro, que era una cosa inocente, ha llegado a convertirse en un motivo de tristeza y de dolor, para hacer más angustiosa la vida del hombre moderno ${ }^{19}$.

Más adelante, Molina prosigue expresando que "[...] Gran parte de la angustiosa psicosis contemporánea viene de esas bibliotecas donde están acumulados los ideales, dudas y dolores de los siglos"20, sin embargo, a pesar de este aparente desencanto frente al libro, Molina concluye su artículo pronunciando una frase alentadora sobre la crucial importancia de las lecturas, al exclamar:

¡Pero tales bibliotecas son nada menos que la forma concreta y tangible de la civilización!'21.

De esta manera, se percibe entonces que Molina denosta las "lecturas malsanas", que en el caso de América Latina, especialmente a partir del Romanticismo, dieron lugar a una especie de "práctica ritualista" en la que algunos creadores y lectores asumían en la vida real un designio caracterizado por un tono pesimista y fatalista; por la voluntad de acceder a la soledad; la frenética búsqueda del amor imposible y una constante relación con la muerte, al grado que una buena parte de los poetas del Romanticismo latinoamericano y hondureño acabaron con sus vidas por la vía del suicidio, tendencia llamada algunas veces como "El mal del siglo", aludiendo a la novela de Nordau².

19 Ibíd., p. 180. El subrayado es nuestro.

20 lbíd., p. 181.

21 Ibíd., p. 181.

22 En Honduras, la mayor parte de sus poetas Románticos acabaron suicidándose, como por ejemplo Julio César Fortín (1866-1894), Jesús Torres Colindres (1878-1896), Félix Tejada (1868-1896), Manuel Molina Vigil (1853-1883) y José Antonio Domínguez (1869-1903). Cfr. Funes, José Antonio, Froylán Turcios y el Modernismo en Honduras... Op. Cit., p. 27. Sobre la temática de la muerte en la obra de algunos escritores hondureños, puede verse: Medina Durón, Juan Antonio, El tema de la muerte en la novelística de Froylán Turcios, Tegucigalpa, Tesis de Grado, Escuela Superior del Profesorado Francisco Morazán (ESPFM), 1973. Con relación a Molina, todavía existe la polémica de si se suicidó 
En este aspecto, Molina manifiesta el impacto de esas lecturas nocivas en su artículo "Por qué se mató Domínguez", indicando que uno de los factores que condujeron a su amigo José Antonio Domínguez a la muerte fue debido a "[... L Las lecturas malsanas y disolventes de que nos hemos impregnado todos los jóvenes cerebrales de la América Latina, contribuyeron poderosamente a su desnivelación moral. Recuérdese el caso idéntico de José Asunción Silva, poeta de un sentimentalismo morboso, extraviado en una filosofía dolorosa y sensual, que le condujo lógicamente a la liberación voluntaria"23. Por eso, Molina aconsejaba a los lectores que "[... ] Tales lecturas deben tomarse como simples deportes, no como guías mentales, porque llevan a la deserción de la lucha por la vida, al aniquilamiento del yo, al nirvana total"24.

Fuera de esa aversión y crítica a las "lecturas malsanas", es evidente que Molina fue un gran amante de los libros y de las "buenas lecturas", en especial, las "lecturas en soledad". Como ya vimos, algunas veces dichas lecturas le provocaban una profunda tristeza y melancolía, pero en otras ocasiones, le inspiraban más bien sentimientos de éxtasis y hasta morbo. Así lo deja entrever en su relato "El grillo de la muerte", en donde expresa en una hermosa prosa poética que:

En mi cuarto de estudiante... leía yo un libro rebosante de vida, de juventud y de amor, que narraba, el idilio carnal de dos amantes, dos náufragos de un buque europeo, que, bajo los follajes umbríos, ebrios de sol, de amor y de deseos, unían sus labios en la ribera de una isla verde, ceñida de un mar azul, llena de lagos minúsculos, de musicales cascadas, de pájaros

\footnotetext{
o murió por los excesos del alcohol y la morfina. Al respecto, Julio Escoto apunta que Julián López Pineda, quien fue compañero de Molina en los últimos días de su vida, refería que "Molina había intentado suicidarse días antes del 2 de noviembre. Había solicitado de un médico inyectarle 12 centígrados de morfina, para dejar el licor y recobrar la lucidez... Pero el mismo día, visitó dos médicos más, quienes le aplicaron 12 y 8 centígrados, respectivamente. Arrepentido, buscó a López Pineda, quien lo mantuvo despierto hasta disipar el coma...". Cfr. TMC, edición de Julio Escoto, p. 22. En suma, las pistas apuntan más a un posible suicidio.

${ }^{23}$ TMC, edición de Julio Escoto, p. 205.

24 Ibíd., p. 205. El subrayado es nuestro.
} 
amorosos y de gacelas lascivas... Y sentía leyendo aquellas páginas ardientes, por las cuales pasaba un hálito de terrible voluptuosidad, que la sangre de mis veinte años se aceleraba en mis puños, y subía a golpes mis sienes. $Y$ todo mi ser se llenaba de aquella isla, bebía sus emanaciones. La de la playa llena de mariscos, la de los bosques y la tierra, la de la carne joven, palpitante, desnuda al viento y al sol... y oí el aullido de gata en celo de la mujer... ${ }^{25}$.

En general, se percibe que las lecturas de Molina lo llevan a experimentar desde estados melancólicos y depresivos, hasta estados de ánimo caracterizados por la euforia y el optimismo. Este contraste, de acuerdo a Alfredo León Gómez, también se vislumbra en la obra literaria de Molina, la cual estuvo signada por la reiteración de una serie de temas o "constantes psicológicas" muy frecuentes en sus creaciones, especialmente los temas de la muerte, la tristeza, la melancolía, la nostalgia y el auto-desprecio (como en los poemas "A una muerta" y en "La fosa olvidada", donde se observan todas las constantes psicológicas); pero también en algunos casos, persisten temas opuestos a los anteriores, como la euforia, el optimismo, la ampulosidad y la pomposidad (como en sus poemas "Salutación a los poetas brasileiros" y "Águilas y Cóndores". Esta dualidad llevó a León Gómez a definir la personalidad de Molina con un "desorden depresivo bipolar con hipomanía” 26.

Finalmente, también hay que señalar que a partir de sus "lecturas en soledad", Molina analizó parte de la obra literaria que se estaba gestando en Honduras entre finales del siglo XIX y comienzos del $X X$, es decir, de la producción escrita entre el Romanticismo y el Modernismo, y en este sentido, se volvió en ocasiones en un crítico implacable de algunas de esas obras. Por ejemplo, al leer la novela Angelina, de Carlos F. Gutiérrez, la enjuició severamente, al grado que argumentó sobre la misma que era un:

\footnotetext{
${ }^{25}$ Ibíd., pp. 181-182.

${ }^{26}$ León Gómez, Alfredo, Aspectos psicológicos de la obra literaria de Juan Ramón Molina, Tegucigalpa, Editorial Universitaria, Colección Cuadernos Universitarios, $N^{\circ}$ 73, $1^{a}$ edición, 1990, pp. 13-14.
} 
Librejo cursi y pedante, indecente y chabacano, que siempre tengo a mano cuando me tomo un purgante... ${ }^{27}$.

La pluma de Molina se vuelve más devastadora con Teodoro Aguiluz. La poesía de este autor, como la de todos los románticos hondureños, había recibido influencias de Zorrilla y Espronceda. Y Molina considera que Aguiluz, "con su estilo ampuloso y pedante tomó de los españoles todos los defectos y ninguna de sus cualidades"28. Entre esos defectos que el crítico advierte, se encuentra "la manía de lo esdrújulo. Aguiluz esdrujulea sin ton ni son"; y de esto ofrece algunos ejemplos: "clamor lúgubre, estridor horrísono, escudo aurífero, aspecto lóbrego, gloriosos vítores" ${ }^{29}$. Más adelante, califica a los autores románticos de tener "imaginación dislocada y una extravagante verbosidad lírica”. Por último, con la poesía de Francisco Vaquero no parece menos piadoso, y la primera línea de su crítica resulta muy elocuente: "Vaquero es un poeta muy inferior a Aguiluz". Molina llega a calificar algunos versos de Vaquero como "pura prosa rimada”. Al final, se despide de Vaquero con una ironía que, más allá de la irreverencia, define muy bien las críticas lecturas que había hecho de la creación poética que se había hecho en el país: "Que la tierra sea blanda [al poeta Vaquero], aunque la crítica será siempre dura con él" 30 .

En suma, Molina adquiere en sus "lecturas en soledad" desde sensaciones de melancolía y pesimismo, hasta goces carnales y libidinosos pero también, emociones y aprendizajes eruditos a través del cultivo de lecturas científicas y filosóficas como las de Darwin, Nietzsche, Schopenhauer, Renán, etcétera.

\footnotetext{
${ }^{27}$ Véase: Rivera y Morillo, Humberto, Juan Ramón Molina, San Pedro Sula, Impresora La Cultura, 1966, p. 50. Ya otros autores -como Julio Escoto-, han señalado la propensión de Molina de enfrascarse en inútiles y conflictivos debates periodísticos con otros escritores de la época, en los que acudió a una crítica demoledora y en ocasiones rayando en la invectiva y hasta el escarnio, especialmente contra los autores adscritos al Romanticismo. Escoto afirma que Molina "[...] derrochó así gran parte de su talento en este inconsecuente combate de prensa". Cfr. TMC, edición de Julio Escoto, p. 25.

${ }^{28}$ Citado en: Funes, José Antonio, Froylán Turcios y el Modernismo en Honduras, Tegucigalpa, Litografía López/ Edición del Banco Central de Honduras (BCH), $1^{\text {a }}$ edición, 2006, p. 74.

${ }^{29}$ Ibíd., p. 74.

30 Ibíd., pp. 74-75.
} 
Por su parte, el otro escritor importante que práctico con preferencia las "lecturas en soledad" fue Froylán Turcios"1, uno de los escritores hondureños más famosos de la primera mitad del siglo XX, quien perteneció a la generación de pensadores antiimperialistas latinoamericanos conformada entre otros por Manuel Ugarte, José Enrique Rodó, Víctor Raúl Haya de la Torre y José Vasconcelos, con quienes tuvo una fluida correspondencia. Sin duda alguna, Turcios es el más ferviente nacionalista hondureño de toda la historia, tanto por su labor política en contra del imperialismo, así como por el radicalismo de su pensamiento.

Fotografía de Froylán Turcios en Londres, de 1929. (Incluida en: Funes, José Antonio, Froylán Turcios y el Modernismo en Honduras, Tegucigalpa, Litografía López/Ediciones del Banco Central de Honduras (BCH), $1^{\text {a }}$ edición, 2006).

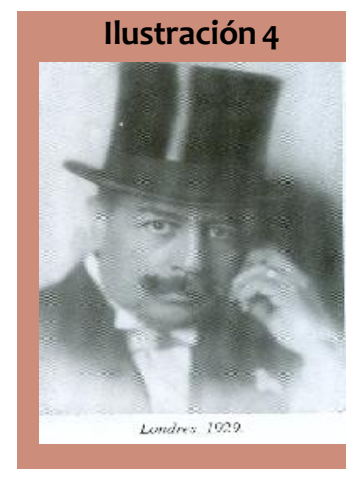

Sin duda alguna, Turcios fue de los escritores más importantes de Centroamérica en la primera mitad del siglo XX, y su labor cultural que transcurrió desde literato hasta periodista, librero, promotor cultural y editor de revistas- demuestra que fue uno de los centroamericanos que acumuló más lecturas en las primeras décadas del siglo pasado.

\footnotetext{
${ }^{31}$ Froylán Turcios nació en 1874 en Juticalpa, departamento de Olancho, el más extenso y el más rico en producción agropecuaria del país, y murió en el exilio en San José de Costa Rica en 1943. Político y literato fecundo, perteneció a la corriente "Modernista". En distintos gobiernos de principios del siglo XX, fue Ministro de Gobernación (Interior), así como Encargado de Negocios en Francia y Delegado por Honduras ante la Asamblea de la Sociedad de Naciones. En su producción literaria destacan entre otras obras: Mariposas y Floresta sonora en verso y El vampiro y Cuentos del amor y de la muerte en narrativa. Tuvo una labor sobresaliente en el campo periodístico, fundando y dirigiendo periódicos como "El Tiempo", “El Heraldo" y "El Nuevo Tiempo", así como las revistas "El Pensamiento", "Esfinge", "Ariel” y "El Boletín de la Defensa Nacional", éstas dos últimas, trincheras desde donde emanaron corrientes de tinta en contra del imperialismo y la intromisión de los Estados Unidos en la política vernácula centroamericana.
} 
En el caso de Turcios, es interesante advertir que su pasión por la lectura se inició desde sus años de infancia, y es más sorprendente aún por el hecho que su primera formación literaria realmente la desarrolló en su natal Juticalpa, una región que naturalmente presentaba desventajas frente a la "letrada" Tegucigalpa en cuanto a la dotación de libros y lecturas. En todo caso, Turcios se las ingenió para "devorar" todos los textos que encontró en su tierra olanchana.

Pero, ¿de dónde le nació a Turcios su pasión por la lectura y la creación literaria?. Esta interrogante nos la responde él mismo en sus famosas Memorias, quizá una de las mejores prosas escritas en toda la historia de la literatura hondureña. En ellas, Turcios relata que animado por su hermana mayor Rafaela "Lalita" Turcios, dio sus primeros escarceos con las lecturas y escritos en casa de su abuela materna, Rafaela Valenzuela:

La casa... poseía también dos extensos patios cubiertos de árboles, rosales y diamelas. Ocupaba el centro del primero un espléndido tamarindo centenario. Sentado en sus altos ramajes -a los que aprendí a subir con mucha agilidad- devoré los iniciales volúmenes de mi predilección y escribí mis primeros versos ${ }^{32}$.

Como se observa, desde niño Turcios busca saciar sus lecturas en lugares solitarios, en este caso, un árbol, desde luego un espacio placentero y a la vez lúdico para los niños. A la vez, es importante resaltar la influencia que desde entonces jugó su hermana Lalita en la vida literaria de Turcios. Así, confiesa que Lalita "[... ] me defendía cuando mi madre me castigaba, ofreciéndose para que le pegara en mi lugar; encargándose del arreglo de mi ropa y de todo cuanto me atañía; contándome cuentos, leyéndome lindas historias, despertando en mi la pasión por las letras, que concretó luego la más imperiosa necesidad de mi vida... La menor de mis contrariedades la hacía llorar y verme contento era su ventura"33.

\footnotetext{
32 Turcios, Froylán, Memorias, Tegucigalpa, Editorial Universitaria, $1^{a}$ edición, 1980, p. 29. 33 Ibíd., p. 27.
} 
Otro personaje que tuvo una importante intervención en la inicial formación literaria de Turcios y en su interés por la lectura fue el profesor cubano Francisco de Paula Flores, el maestro "Pancho"34, quien fue su profesor en la escuela de Juticalpa, el cual, ante las impulsivas lecturas que Turcios realizaba ya desde los 9 años, se sorprendía de la calidad de las lecturas que éste hacía; el mismo Turcios manifiesta que el maestro "Pancho" le expresaba que "El exceso de lectura te daña... estás apenas en la edad de los barriletes, los mables y los trompos, pero no de los libros que no sean los de tus clases" 35 .

En este sentido, es interesante observar que siendo un niño de apenas 9 años, Turcios ya muestra su incesante propensión a la lectura de autores preferidos más bien por adultos. Así, declara en sus Memorias que:

\section{Efectivamente, a los nueve años había yo devorado la biblioteca} de mi padre, compuesta como de seiscientas obras de diverso género, y todas las novelas que podía atrapar, por compra o préstamo, en la ciudad. Todos los volúmenes de Verne, Sué, Mayne, Red, Walter Scott, Dickens, Balzac, Dumas, etc., que existían en Juticalpa, pasaron por mis manos en aquel tiempo, en rápida rotación, porque mi sed de lectura no se saciaba nunca. Contribuyó a ello Lalita, quien sumergíase, en las horas que le dejaban libres sus estudios, en la misma deliciosa tarea espiritual. En la época en que los niños, aun en los países más cultos, no han conocido más libros que los textos de enseñanza, yo, sin salir de mi región materna, sabía, con amplios detalles, la historia de los más grandes hombres, poetas, políticos, guerreros, filósofos; de los varones más ilustres en las ciencias, las artes y las letras; y vivía, más que la vida normal, la existencia fantástica

\footnotetext{
34 Francisco de Paula Flores nació en Matanzas, Cuba, y llegó a Honduras con los exiliados cubanos que fueron recibidos por el presidente Soto, y consagró más de dieciocho años a la educación en Honduras, donde murió en 1891. Turcios reconoció pocos años después la influencia de su maestro, señalando que: "Todos los jóvenes de nuestro departamento que han conquistado un título de honor, fueron sus discípulos". Cfr. Turcios, Froylán, Todos los cuentos, Edición de José Antonio Funes, Tegucigalpa, Secretaría de Cultura, Artes y Deportes/Edicult, $1^{\text {a }}$ edición, 2005, p. 18.

35 Turcios, Froylán, Memorias... Op. Cit., p. 36.
} 
que se desarrolla en las leyendas de todas las regiones del planeta $^{36}$.

Más adelante, Turcios agrega que leía incluso sin hacer distinción en la calidad literaria de los textos, optando por leer todos los libros que cayeran a mano:

Mi criterio naciente se perdía en aquellas lecturas heterogéneas sin apreciar la calidad de los autores. Todos contribuían a amenizar mis noches y a todos estaba agradecido; y no fue sino cuando mi adolescencia iluminó mi cerebro con una luz más brillante, sutilizando mi emoción, que empecé a aquilatar el valor de cada uno. En mi casa nadie se opuso a aquella precoz avidez. Mi padre, por el contrario, la fomentó cuanto pudo obsequiándonos con frecuencia, a Lalita y a mí, con innumerables obras clásicas, y obteniendo para nosotros cuantas le fue posible en la capital, sin hacer caso de las observaciones del maestro ${ }^{37}$.

La sed de lecturas de Turcios llegó a ser tan irresistible, que cuando agotó todas las lecturas existentes en la ciudad, sintió un sufrimiento similar al de los adictos al alcohol o a las drogas, según confiesa con sus propias palabras: "[... ] llegó un día en que nos quedamos sin este insustituible alimento. Los mil quinientos volúmenes diseminados en Juticalpa habían pasado por nuestros ojos y carecíamos de otros nuevos con que satisfacer nuestra necesidad primordial. Sufrimos entonces el tormento de los morfinómanos viendo terminada la droga que nos embriagaba de emoción"38.

Como se ve, Turcios -siendo aún un niño-, lee con fruición de manera sorprendente más de 1,500 libros, y se lamenta de su suerte al quedarse sin más lecturas disponibles. Las lecturas le producen "emoción” y le alimentan su vida más que cualquier otra cosa en el mundo. Afortunadamente, al poco tiempo, Turcios revela que tuvo

\footnotetext{
${ }^{36}$ Ibíd., p. 36 . El subrayado es nuestro.

37 Ibíd., p. 36. El subrayado es nuestro.

${ }^{38}$ Ibíd., p. 36.
} 
la suerte de encontrarse con un curioso personaje -el Lic. Pedro Rivera Bustillo-, quien contaba con una "secreta y selecta biblioteca" que inmediatamente puso a su disposición para que saciara sus lecturas anheladas:

Un domingo iba distraído por una calle, y al pasar frente a los balcones de la casa del licenciado Pedro Rivera Bustillo me detuve, mirando, en el fondo de un cuarto, un armario-escritorio de cristales repleto de libros empastados. ¡Que sorpresa! ¿Pero cómo pudo escaparse a mis búsquedas incesantes aquel magnífico tesoro? Mi corazón latió fuertemente pensando en el placer que sentiría Lalita si le llevara uno de aquellos tomos. ¿Contendrían fábulas de andantes caballeros como las que hicieron perder la razón a don Quijote, o narraciones rusas o novelas inglesas?.

Audazmente penetré por el zaguán y me vi luego en la sala. Al ruido de mis pasos abrióse una puerta lateral y apareció don Pedro. Olía a coñac y su semblante reflejaba satisfacción y humor.

¿¿Qué tal, Froylancito?- exclamó. Por primera vez llegas a mi hogar... -Tu visita es interesada, amiguito. Conozco tu vicio, el más simpático, pero también uno de los más apremiantes. Lo conozco. Tú lo cogiste a los ocho años, yo a los treinta. Rarísimo, único, incomprensible; como que, entre cada millón de espíritus habrá diez que lo gocen y sufran-.

Llevóse la mano al chaleco y con una llave de plata abrió el armario de cristal.

-Ahí tienes mis libros, todos con pastas de cuero. Son doce hileras compactas. Mis obras favoritas, que pedí a España: de autores alemanes, franceses, italianos, rusos, muy bien traducidos. I todas las joyas clásicas de nuestro maravilloso idioma. Te los prestaré con dos únicas condiciones: cuidar de que no se ensucien y llevarlos uno por uno. Tomo leído, tomo devuelto. Emocionado, le di las gracias, y me entregó el primero de las 
obras completas de Chateaubriand.

I así conocimos al creador de Atala y René, luego a Víctor Hugo, Lamartine, Racine, Corneille, Moliere, Goethe, Schiller, Heine, Byron, Moore, Shakespeare, Milton, Dante, Petrarca, Tasso, Tolstoy, Dostoyewsky, Gogol, Ibsen, Björnson, etc. En pleno desorden cronológico.

Mi mayor ilusión fue entonces aislarme en amenos sitios con alguno de aquellos preciosos libros. Los insípidos juegos de mis compañeros de escuela o de vecindario repugnábanme en aquel lapso 39.

De este modo, vemos que Turcios gana el favor de Lic. Bustillo, y tras agenciarse de una selectiva y atrayente literatura, para disfrutarla, se retira a lugares apartados para hacer sus "lecturas en soledad".

Más tarde, ya en su adolescencia, Turcios nos relata en sus Memorias que sus padres lo envían a estudiar a Tegucigalpa, al cuidado de Adolfo Zúniga, en donde se matricula primero en el "Instituto La Unión", y luego en el "Colegio El Porvenir", dirigido por Esteban Guardiola. En Tegucigalpa, ante la disponibilidad de más ambientes para su formación literaria, Turcios declara que "[... mi ansia de lecturas llegó a su extremo" 40 . A los dieciocho años, conoce en la ciudad a su paisano olanchano José Antonio Domínguez, a quien le da a leer sus prosas y versos. Domínguez le elogia algunos versos, y le recomienda estudiar más "[...] gramática... retórica... y más selectas lecturas"41.

\footnotetext{
${ }^{39}$ Ibíd., pp. 37-39. el subrayado es nuestro. Hay que advertir que Turcios por aquel tiempo usaba la forma gramatical "|" en vez de la moderna forma " $\gamma$ ", al igual que muchos intelectuales latinoamericanos, siguiendo la ortografía propuesta en 1823 por Andrés Bello y Juan García del Río, norma que dejó de utilizar en sus escritos a partir de 1939. Cfr. Funes, José Antonio, Froylán Turcios y el Modernismo en Honduras... Op. Cit., p. 34.

${ }^{40}$ Ibíd., p. 45.

${ }^{41}$ Ibíd., p. 85.
} 
Turcios sigue las instrucciones de su amigo y maestro, y desde entonces, inicia una frenética y productiva carrera literaria, dedicada a la poesía, a la narrativa y a la lectura. Entre finales del siglo XIX y comienzos del XX, combina su carrera política con las letras, y ya ha publicado sus libros Mariposas (1896), Renglones (1899), Almas trágicas (1900), El Vampiro (1910) y Hojas de otoño (1904), que a juicio de José Antonio Funes, es la obra que consagra a Turcios como uno de los mejores creadores de la cuentística hispanoamericana, y lo da a conocer tanto en España como en América Latina. En efecto, a partir de este libro Turcios muestra no solamente los tópicos o temas recurrentes del Modernismo, como la presencia de la mujer fatal, la necrofilia, el incesto, el dandy, el fetichismo y el parnasianismo, sino que exhibe sus influencias literarias, especialmente proveniente de autores como Rubén Darío, Edgar Allan Poe, Villiers de I' Isle Adam, Verlaine, Baudelaire, Mallarmé, Maeterlinck y fundamentalmente de Gabriel D' Annunzio, “II Magnífíco", que para el hondureño siempre fue el más grande escritor de todos los tiempos ${ }^{42}$.

Ciertamente, Turcios es un escritor que devora lo más importante de la literatura universal, pero él mismo confiesa que sus lecturas preferidas fueron siempre Darío, Poe, y fundamentalmente D' Annunzio, que de acuerdo a sus propias palabras, fue un autor que "leyó y releyó hasta saciarse" 43 .

Ya como escritor consagrado, Turcios no solamente sigue leyendo con desenfreno, sino que también incursiona en el floreciente negocio de los libros, abriendo en 1921 su librería "Hispano-América" en Tegucigalpa. Según sus palabras, el negocio "[... ] creció en pocos meses. Amontonaba yo todos los paquetes que recibía de casas editoriales de España, Francia y Alemania, y uno por uno iba abriéndolos, leyéndole los títulos de los libros que contenían el nombre del autor... Fundé aquella librería menos con un fin utilitario que por el deseo de continuar difundiendo en Honduras las obras máximas

\footnotetext{
42 Véase: Turcios, Froylán, Todos los cuentos, Edición de José Antonio Funes... Op. Cit., pp. 6-7. 43 Turcios, Froylán, Memorias... Op. Cit., p. 301.
} 
universales en las ciencias, las letras y las artes" 44 .

Paralelamente al negocio, Turcios avizora la inversión de la librería como una oportunidad de incrementar sus propias lecturas:

[... me daré un lujo estupendo [con la librería]. El de reunir varios millares de magníficos volúmenes para leerlos o releerlos en la paz del campo... ${ }^{45}$.

Incluso Turcios es tan adicto a las buenas lecturas, que en ocasiones se pone renuente a vender a sus clientes algunas obras que le seducían por su rareza, calidad editorial o magnitud literaria:

[... ] con ese singular cariño que siempre he sentido por los libros de mis autores predilectos, cuando algún comprador ignaro, tras revisar las listas en las últimas páginas de Hispano-América, me solicitaba uno de aquellos raros tomos de los que sólo quedaba un ejemplar, rehuía la venta con cualquier pretexto, incómodo por tener que recurrir a un embuste, pero resuelto a no desprenderme de tal tesoro. Así me pasó -recuerdo- con Hombres y Dioses de Paúl de Saint-Víctor, con una exótica edición de las Historias Fantásticas de Poe, en la Eva futura de Villiers de I' Isle Adam, con La Hermética de Rachilde, con las obras de Plotino, Esquilo y treinta más ${ }^{46}$.

Del mismo modo, Turcios manifiesta que a través de la librería "Hispano-América" logró estimular la lectura no solamente en Tegucigalpa, sino en muchos rincones del país, desde donde los clientes le remitían cartas solicitándole lecturas de valía:

Llegó un día en que los grandes libros empezaron a venderse. De los departamentos enviábanme cartas, con el dinero respectivo, pidiéndome gran número de volúmenes: obras de

\footnotetext{
44 Ibíd., p. 300.

45 Ibíd., p. 300. el subrayado es nuestro.

${ }^{46}$ Ibíd., p. 300. El subrayado es nuestro.
} 
sociología, de historia, de imaginación, que yo debería escoger. Lo hacía con estricto cuidado y, con la mejor voluntad, tomando en cuenta la aptitud mental del solicitante. Conservo un extenso legajo en que me dan las gracias por haber acertado en lo que se quería. Un señor me escribió: “"Tengo una mediana instrucción, no soy tonto. Me gustan las cosas justas y que den exacta idea de las comunes realidades. Deseo dos novelas que algo me enseñen y me distraigan". Le envié dos interesantes narraciones de Walter Scott.- A una joven del oriente hondureño que me encargó "tres novelitas. Una de perfecta sencillez e inocencia, otra con un poco menos de estas cosas, y otra más complicada, todas de amor", le remití, marcándole las tres cifras de su escala Pablo y Virginia, de Saint Pierre; Grazielle, de Lamartine y Magali, de Delly. Quedó encantada. Por supuesto que a las muchachas, si eran bonitas, les devolvía el dinero... ${ }^{47}$.

Por otra parte, al parecer Turcios valoró en gran dimensión su nueva actividad como librero, llegando a afirmar que: "El único negocio digno de un hombre de letras, que se vea obligado a ganarse el pan cotidiano en nuestros países de Centro-América -fuera de las faenas de revistas y periódicos, si ellos alguna vez pueden constituir un negocio- es el de librero. Feo el nombre, por su sentido utilitario, pero de noble finalidad esencial" 48 .

Fue tan importante su nueva faena como librero, que inclusive se dio a la tarea de criticar rigurosamente a los libreros que vendían obras literarias de escasa calidad, así como a los lectores aficionados a dichas lecturas superficiales:

Si no fuera porque opino que se debe, a todo trance, procurar la difusión de la palabra impresa, habría hecho campaña en mis diversas publicaciones para que la ley prohibiera que vendiesen libros los que no son aptos para comprenderlos. Los hombres y las mujeres vulgares no los aman, e interesándoles únicamente

47 Ibíd., pp. 300-301.

${ }^{48}$ Ibíd., p. 301. 
como artículo comercial, prostituyen el gusto literario, rebajándolo aún más con la venta de ediciones groseras o pornográficas. Al hombre casi analfabeta le atrae la expresión que esté al nivel de su obscura inteligencia, en ocasiones -como ya lo dije en otra parte-menos despierta que el instinto de algunos animales irracionales provenientes de razas refinadas. Le seducen la procacidad en el lenguaje, los dibujos obscenos, los títulos lúbricos o brutales. I el comerciante obtuso, convertido en librero, a quien nada le importan la inmoralidad y el mal gusto, y que más bien se satisface en la exhibición de tales desvergüenzas, les sirve el plato que sacia su morboso apetito ${ }^{49}$.

Sin duda en esta cita Turcios exhibe la típica actitud de los escritores Modernistas, quienes se autoproclamaron como una casta de espíritu alto y refinado, superior al resto de la sociedad, y aspiraban -frente al predominio de lo vulgar y la soberbia de los poderosossuplantar la "aristocracia del dinero" por la "aristocracia del talento".

Frente a esos "libreros obtusos", Turcios contrapone sus logros en materia de promoción de la lectura en el país, y se vanagloria de sus méritos al afirmar que él vendió la sorprendente cantidad de más de 50,000 libros en el país:

Yo vendí en Honduras, de 1921 a 1928, más de cincuenta mil volúmenes, a precios módicos; con escasas excepciones, obras útiles y bellas. Centenares distribuí en centros culturales y entre personas que los necesitaban y que por su pobreza no podían comprarlos... I las satisfacciones morales y mentales que me producía aquel delicado comercio eran exquisitas y por encima de todo precio. Para un hombre como yo, que desde su infancia tuvo a los libros por íntimos compañeros; para quien la lectura fue algo de su propia naturaleza; que había llegado a la completa comprensión de las altas letras universales -revisar los innumerables catálogos, hacer los pedidos de conformidad con

49 Ibíd., p. 301. El subrayado es nuestro. 
mis deseos y mis gustos, recibir los paquetes, abrirlos, sintiendo la suavidad de las pastas, el olor peculiar del papel recién impreso, ver los títulos nuevos con los nombres de los autores selectos... - constituía un placer profundo, desconocido para ningún otro en mi país ${ }^{50}$.

Es interesante observar la relación casi fetichista que Turcios establece al expresar las sensaciones que le produce el leer, tocar y oler los libros; igualmente, es excepcional la labor de Turcios en esta nueva cultura libresca en el país, llegando a distribuir miles de volúmenes en manos de lectores y centros culturales ávidos de las lecturas sugeridas por el bardo hondureño. Fue tal su pasión por los libros, que incluso llegó promover en Tegucigalpa en 1910 las "Fiestas Gutenberianas", como un homenaje al libro y a Juan Gutenberg, inventor de la imprenta; para tal fin, compuso un "Himno a Guttenberg" -con música de Rafael Coello-, el cual fue cantado en todas las escuelas de la capital el 24 de junio de $1910^{51}$.

En todo caso, es necesario matizar que a pesar de las públicas manifestaciones que Turcios se imputa como promotor de lecturas en el país -lo cual es evidente e innegable-, ciertamente era conciente que la lectura era una práctica simbólica que establecía diferencias entre la casta sagrada de los que pertenecían a la "clase letrada" como él, y el resto de los prosaicos y corrientes lectores. Así lo expresa por ejemplo en un artículo, donde manifiesta que la lectura es uno de los placeres más elevados que puede gozar un escritor que aspire a ser un esteta, deleite que por supuesto estaba exento en las personas de espíritu ordinario y pedestre:

\section{La lectura de obras exquisitas es uno de los placeres más intensos} de que puede gozar el alma del artista. Goce delicado y hondo, que está vedado a la inmensa mayoría de los humanos y que constituye el alimento de los cerebros fuertes.

\footnotetext{
${ }^{50}$ Ibíd., pp. 301-302. El subrayado es nuestro.

51 Véase: Turcios, Froylán, “Himno a Guttenberg”, En: Revista de la Universidad, Tegucigalpa, Tomo II, N ${ }^{\circ}$ 9, 15 de septiembre de 1910, pp. 609-610.
} 
¡Qué inefable emoción invade nuestro organismo leyendo uno de esos libros encantadores, en los que del azulado encaje del estilo surgen divinas formas de belleza, como las curvas de un mórbido cuerpo bajo el cincel, en un trozo de mármol! ¡Qué alegría silenciosa nos conmueve después de la lectura de una de esas páginas únicas, en que los grandes intelectuales ponen su espíritu y su sangre, embriagándonos de entusiasmo, abriendo ante nosotros la misteriosa puerta de los sueños, y mostrándonos, en un relámpago ilusorio, el secreto sutil de la palabra! Páginas que semejan luminosas pedrerías; raros ramilletes de flores sobrenaturales; cuadros mágicos, en donde están encerradas las más recónditas manifestaciones estéticas... En ellas cada voz tiene un alma que tiembla y canta y dice su secreto. Un alma leve, formada de músicas, de matices y de perfumes. Alma que vibra hondamente en algunos versos inmortales, y que debió volar -como una abeja de oro- en el cerebro del poeta creador ${ }^{52}$.

En fin, podemos concluir que Turcios fue uno de los lectores más insaciables en este periodo de la historia hondureña, mostrando una precocidad hacia la lectura desde sus infantiles años en tierras olanchanas. A lo largo de sus años, se empapó de lo más selecto de la literatura universal, sin embargo, sus lecturas preferidas fueron más bien las de los escritores románticos, y en su etapa de madurez creativa, los autores decadentistas y simbolistas franceses, y luego, los modernistas españoles y latinoamericanos, aunque tuvo como obras de cabecera a Darío, Poe, Verlaine, Baudelaire, Mallarmé, Maeterlinck y especialmente D' Annunzio, escritores a los que descubrió primordialmente a través de "lecturas en soledad".

\footnotetext{
52 Véase: Turcios, Froylán, Páginas del ayer, Tegucigalpa, Secretaría de Cultura, Artes y Deportes, Colección Biblioteca Básica de Cultura Hondureña, № 16, $2^{\text {a }}$ edición, 2000, pp. 154-155. El subrayado es nuestro.
} 


\section{B) Lecturas en público: las lecturas familiares en casa de Marco Antonio "Toño" Rosa.}

El escritor Marco Antonio Rosa, más conocido como "Toño Rosa"53, relata en algunas de sus más importantes obras, como en Tegucigalpa, ciudad de remembranzas y en La Tegucigalpa de mis primeros años que junto a su madre -Rosa Cubas de Rosa- y otros sobresalientes personajes de la ciudad -como el ex presidente Policarpo Bonilla, el abogado Ricardo Pineda y las señoras Francisca "Paquita" de Gómez Osorio y doña Ana de Gómez-, se juntaban todas las tardes en la sala de su casa a realizar "lecturas en público" desde más o menos el año de 1918. Estas lecturas en voz alta frecuentemente se hacían con los periódicos, revistas y en algunas ocasiones también libros.

En estas reuniones -que naturalmente eran más habituales en las clases adineradas- nació una identificación entre los miembros del grupo, que compartían el interés por lo que leían en esos textos, y se generaban entre ellos lazos de relación que iban más allá del contenido del periódico mismo. En efecto, se congregaban casi a diario para hacer sus acostumbradas lecturas, convirtiéndose en una norma de urbanismo y también en necesidad, donde los presentes empezaron a ensayar experiencias, debates, ideas y actitudes, hasta constituir una comunidad de interpretación.

En efecto, cierto día de 1928 en que doña Rosa Cubas de Rosa se encontraba relatando los sucesos cotidianos de la Tegucigalpa de inicios del siglo XX, especialmente los referentes a la llegada de la compañía de teatro mexicana "UNDA" a la ciudad y de la construcción de la carretera del sur, doña Francisca de Gómez comentó a los demás contertulios que doña Rosa recordaba todos

\footnotetext{
53 Marco Antonio “Toño" Rosa nació en Tegucigalpa en 1899 y falleció en la misma ciudad en 1983. Provenía de una familia acomodada y de abolengo en la ciudad, y desarrolló una extensa obra literaria dentro de la corriente del "criollismo". Entre sus obras más reconocidas destacan Tío Margarito (1953); Mis tías las Zanatas; Humor criollo (1957); Embalsamando recuerdos (1959); Honduras de Honduras (1961); Tegucigalpa, ciudad de remembranzas (1968); Los brujos (1969) y La Tegucigalpa de mis primeros años (1972). Cfr. Argueta, Mario, Diccionario de escritores hondureños, Tegucigalpa, Editorial Universitaria, Colección Letras Hondureñas, Nㅜ 71, $1^{\text {a }}$ edición, 1998, pp. 197-198.
} 
esos eventos porque:

Tiene memoria privilegiada, pero yo más creo que ella pasa hojeando su libro de recortes de diarios de principios de siglo que en otras ocasiones me ha enseñado, así que, si deseamos remontar nuestros recuerdos a aquella época, mejor sería que Toño nos trajese el referido álbum. Podremos entonces comentar sin esforzar nuestras mentes, las noticias más importantes de aquel inolvidable tiempo54.

Doña Rosa replicó a su amiga que "esta mañana... estuve leyendo sobre la primer visita que en este siglo hizo a Tegucigalpa dicha compañía, y es por eso que recordé tanto detalle. Ve, Antonio, a traer los recortes a que se refiere Paquita, y que quizá al doctor Pineda le guste que leamos" 55 . Acto seguido, Toño Rosa buscó los recortes de periódicos de su madre, y nos refiere que:

Hojeado el álbum que en su mayoría contenía recortes del "Diario de Honduras" [que era editado por el poeta Juan Ramón Molina], mi madre inició la lectura:

"19 de febrero de 1901. Dentro de muy corto tiempo se concluirá el trayecto de la carretera de esta ciudad a Sabanagrande. En la actualidad hay trabajando 1,600 hombres. El general Terencio Sierra debe sentirse no sólo satisfecho, sino orgulloso de su obra" ${ }^{56}$.

Más adelante, los compañeros de lectura siguieron leyendo y comentando otras noticias destacadas de ese año de 1901, como el fallecimiento del Obispo Manuel Francisco Vélez; la inauguración de la sociedad cultural "Aurora del siglo XX"; las funciones de zarzuela en casa de la familia Lazo; las presentaciones del mago y prestidigitador mexicano Francisco López; las festividades religiosas

\footnotetext{
54 Rosa, Marco Antonio, La Tegucigalpa de mis primeros años, Tegucigalpa, 1972, p. 42.

55 Ibíd., pp. 42-43.

${ }^{56}$ Ibíd., p. 43. Curiosamente, en esas labores de construcción de la carretera del sur, el poeta Molina fue enviado a realizar trabajos forzados por el presidente Sierra, en vista que había publicado en ese mismo periódico el artículo "Un hacha de afilar", que a juicio del mandatario, era un libelo en contra del gobierno.
} 
del Corpus Cristi y la concesión de becas a tres jóvenes hondureños para ir a estudiar a al Colegio Militar de Chapultepec en México entre otras noticias.

Curiosamente, Toño Rosa nos relata que la lectura es intercalada entre los contertulios, y así, su madre, en un momento de la lectura, le manifiesta:

"Toma, Antonio... continúa tú con la lectura; voy a extraer cigarrillos y café caliente".

"Muerte de un niño ocurrida el 30 de marzo de 1902. Hoy a las 12 a.m. falleció en esta capital el niño León Rosa, hijo del señor Francisco A. Rosa y su señora esposa...". "Y aquí hay otra información... que seguramente a mi madre no habrá gustado. Está fechada el 1 de diciembre de 1902; se lee así:

Anoche falleció en esta ciudad don Tranquilino de la Rosa, víctima de un balazo que le infirió su mejor amigo y compañero de cuarto, Juan Ramón Garmendia"57.

Podemos observar que los compañeros de lectura comparten noticias y anécdotas que van desde sucesos cotidianos, como algunas diversiones, festividades religiosas y avisos luctuosos, hasta eventos en los que participaron familiares o allegados. De este modo, es evidente que las lecturas se realizan con la finalidad de evocar un pretérito cercano pero añorado, en el que se trata de ligar el presente con el pasado, pero también con la finalidad de que cada uno de los oyentes emitiera su propia opinión respecto a las notas.

Sin embargo, no solamente se leen pasajes cotidianos o corrientes, sino que también se comentan artículos sobre el acontecer político del país, punto que desde luego incrementa las discusiones con relación a los otros temas más regulares o triviales. Así, Toño Rosa prosigue la lectura de los periódicos dirigiendo la atención en las notas políticas:

57 Ibíd., p. 46. 
-Bueno, aquí hay una información política que a todos debe interesar, ya que se trata de las elecciones presidenciales con tres candidatos a la cabeza. Sírvanse escucharla:

"20 de diciembre de 1902. En el resultado final para las elecciones presidenciales, ninguno de los tres candidatos obtuvo mayoría absoluta... Como el General [Manuel] Bonilla creyera que [Juan Ángel] Arias y [Marco Aurelio] Soto trataban de adueñarse del poder, ya que, unidos en el Congreso se confabulaban contra él, su rebelión no se hizo esperar y así principió en la Isla de Amapala, el 1 de Enero de 1903, culminando con la entrega de la plaza de Tegucigalpa el 13 de abril de dicho año" ${ }^{58}$.

De este modo, los lectores describen la noticia de esas famosas elecciones de 1902 y la subsiguiente guerra civil que llevó al poder al general Manuel Bonilla59. La lectura del acontecimiento naturalmente que levantó las pasiones en el grupo, unos apoyando la acción de Bonilla y otros censurándola. Finalmente, la reunión y lectura en alta voz se disolvió con la inesperada llegada de otros visitantes.

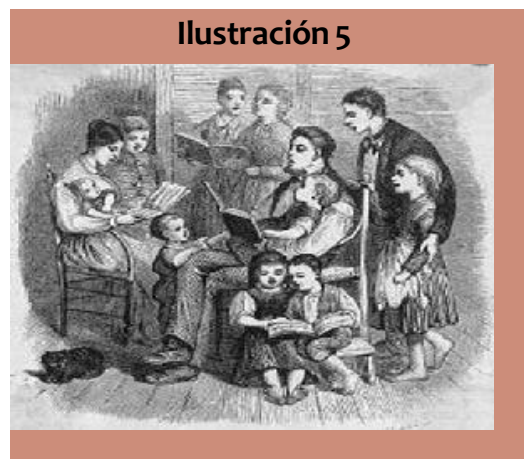

La lectura en alta voz o lectura pública, generalmente entre grupos de amigos o familiares, se empezó a manifestar en Tegucigalpa entre fines del siglo XIX y a principios del XX, especialmente en familias acomodadas como la de Toño Rosa.

Por otro lado, esta "lectura pública" alrededor de las clases pudientes de la ciudad no significa que solamente en esos estratos

\footnotetext{
${ }^{58}$ Ibíd., p. 47.

59 En esos comicios, Bonilla alcanzó 28,550 votos; Arias 25,118 y Soto apenas 4,857. En vista que Bonilla no alcanzó la mayoría absoluta que estipulaba la Constitución de 1894, impulsó la rebelión que le condujo al poder con el apoyo de los presidentes Regalado de El Salvador y Zelaya de Nicaragua. Cfr. Mariñas Otero, Luis, Honduras, Tegucigalpa, Editorial Universitaria, Colección Realidad Nacional,

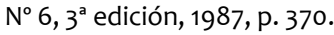


se haya leído; también accedieron a este tipo de lecturas en voz alta cada vez más los sectores medios, y en menor medida, las clases bajas. En este caso, los sectores marginados de la sociedad encontraban más dificultades para acceder a las lecturas debido al alto grado de analfabetismo, así como al todavía elevado precio de los libros y periódicos para sus bolsillos; no obstante, aparecieron algunas opciones que posibilitaron el desarrollo de "lecturas en público" para estos sectores. Una de las principales fueron las barberías para caballeros, en donde los dueños de los establecimientos ponían a disposición de los clientes no solamente periódicos, sino también revistas y otros textos para que leyeran mientras esperaban su turno. Esta práctica fue habitual en Honduras hasta la década de 1980. El mismo Toño Rosa nos cuenta que en la década de 1910, existían varias barberías adonde la gente acudía no solo a cortarse el pelo o afeitarse, sino también a leer y discutir las noticias de los periódicos. Las de clase alta eran la "Siglo XX" de Atanasio Valle, "La Americana" de Pedro Cubas Turcios, y "El Comercio" de Isidoro Soto; por su parte, las barberías a las que acudía el resto de la sociedad eran "La Lucho" y especialmente la barbería de "Jesús Midajita" en Comayagüela"60.

Al igual que en Costa Rica y otros países centroamericanos, en Honduras otros centros de tertulia y posiblemente de lectura y discusión colectiva fueron los incipientes centros artesanales como talleres automotrices, zapaterías, talabarterías, sastrerías y las imprentas. En éstas últimas en particular, a diferencia de otros oficios, los operarios tenían como requisito obligatorio para laborar, el saber leer y escribir, de modo que tales lecturas podrían haber generado opiniones dispares y discusiones que no están documentadas ${ }^{61}$.

La lectura en voz alta en los talleres y fábricas no es una práctica nueva en América Latina. Según Manguel, la experiencia se inició en Cuba en la sexta década del siglo XIX. El gestor de esta práctica fue

\footnotetext{
${ }^{60}$ Rosa, Marco Antonio, Tegucigalpa, ciudad de remembranzas... Op. Cit., pp. 79-80.

${ }^{61}$ Vega Jiménez, Patricia, Una aproximación a la historia de la lectura en Costa Rica (1900-1930), San José de Costa Rica, Universidad de Costa Rica (UCR), 2004, p. 25.
} 
Saturnino Martínez, cigarrero y poeta, quien buscando resolver el obstáculo del analfabetismo que afectaba la difusión de su periódico obrero "La Aurora”, emprendió la tarea de buscar lectores en los centros de trabajo. La labor consistió en leer en voz alta durante horas mientras los obreros efectuaban sus tareas. El lector recibía una paga adicional que salía de los bolsillos de los mismos trabajadores. El material de lectura pronto rebasó "La Aurora", y "[... ] abarcaba desde opúsculos políticos y libros de historia a novelas y colecciones de poesía tanto modernas como clásicas", y aún trascendió hasta más allá del siglo $\mathrm{XX}^{62}$.

En síntesis, en Honduras, además de las "lecturas en soledad", también se manifestaron en el periodo estudiado "lecturas en público", las cuales llegaron a ser más frecuentes al interior de las casas de familias adineradas o de abolengo, como el caso de la familia de Toño Rosa; empero, también los sectores de las clases media y baja empezaron incipientemente a gozar de algunos espacios en los que se desplegaban lecturas colectivas, como en los cafés, las tertulias culturales en colegios y universidades, además de las que se hacían en barberías, talleres, fabricas, imprentas, etcétera. En este sentido, la práctica de la lectura en Honduras en el periodo estudiado estuvo relacionada con varios procesos derivados a partir de la Reforma Liberal de 1876, pero también, a procesos de transformación cultural que se expresaban a nivel regional y mundial. Podemos concluir que en este lapso de la historia hondureña, los libros y las lecturas se incrementaron notablemente en el país en comparación al período colonial y a la primera etapa republicana. La práctica de la lectura pasó paulatinamente de la de carácter religioso y devoto, a las lecturas de temas cada vez más profanos, científicos, literarios y seculares.

\footnotetext{
${ }^{62}$ Manguel, Alberto, Una historia de la lectura, Madrid, Alianza Editorial, 2005, p. 165.
} 


\section{Bibliografía y Fuentes}

ANDERSON IMBERT, (1993), Enrique, Historia de la literatura hispanoamericana: La Colonia. Cien años de República, México DF, Fondo de Cultura Económica (FCE), Colección Breviarios, $N^{\circ} 89$, Tomo I, $8^{\text {a }}$ reimpresión.

ARGUETA, Mario, (1998), Diccionario de escritores hondureños, Tegucigalpa, Editorial Universitaria, Colección Letras Hondureñas, $N^{\circ} 71,1^{a}$ edición.

ASTURIAS, Miguel Ángel, (1959), “Juan Ramón Molina, poeta gemelo de Rubén", En: Antología de Juan Ramón Molina, San Salvador, Ministerio de Educación.

BAQUERO, Gastón, (1991), Indios, blancos y negros en el caldero de América, Madrid, Ediciones de Cultura Hispánica.

CASTILLO, Roberto, (2000), Filosofía y pensamiento hondureño, Tegucigalpa, Editorial Universitaria, Colección Docencia, $N^{\circ} 72,1^{\mathrm{a}}$ edición.

DARío, Rubén, (1998), Prosas profanas, Prólogo de Antonio Gamoneda, Madrid, Alianza Editorial, Biblioteca Conmemorativa del 30 Aniversario de Alianza Editorial.

“Al partir Mayorga Rivas", En: Darío, Rubén, Poesías completas, Edición de Alfonso Méndez Plancarte, Madrid, Aguilar, 1975.

ESCOTO, Julio (Selección, introducción y notas), (1977), Juan Ramón Molina: Tierras, mares y cielos, San José de Costa Rica, Editorial Universitaria Centroamericana (EDUCA), Colección Aula, $1^{\text {a }}$ edición.

FUNES, José Antonio, (2006), Froylán Turcios y el Modernismo en 
Honduras, Tegucigalpa, Litografía López/ Edición del Banco Central de Honduras $(\mathrm{BCH}), 1^{\text {a }}$ edición.

LEÓN GÓMEZ, Alfredo, (1990), Aspectos psicológicos de la obra literaria de Juan Ramón Molina, Tegucigalpa, Editorial Universitaria, Colección Cuadernos Universitarios, $N^{\circ} 73,1^{\mathrm{a}}$ edición.

MANGUEL, Alberto, (2005), Una Historia de la lectura, Madrid, Alianza Editorial.

MARIÑAS OTERO, Luis, (1987), Honduras, Tegucigalpa, Editorial

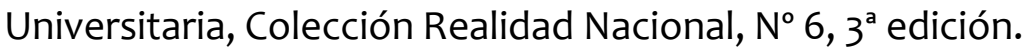

MEDINA DURÓN, Juan Antonio, (1973), El tema de la muerte en la novelística de Froylán Turcios, Tegucigalpa, Tesis de Grado, Escuela Superior del Profesorado Francisco Morazán (ESPFM).

MOLINA, Juan Ramón, “Nietzsche”, En: Molina, Juan Ramón, Prosas, Tegucigalpa, Secretaría de Cultura y Turismo, Colección Biblioteca Básica de Cultura Hondureña, N² 2, 2 edición, 1984.

OQUELÍ, Ramón, (1985), Los hondureños y las ideas, Tegucigalpa, Editorial Universitaria, Colección Cuadernos Universitarios, $\mathrm{N}^{\circ}$ $46,1^{\text {a }}$ edición.

RIVERA Y MORILLO, Humberto, (1966), Juan Ramón Molina, San Pedro Sula, Impresora La Cultura.

ROSA, Marco Antonio, (1972), La Tegucigalpa de mis primeros años, Tegucigalpa.

TURCIOS, Froylán, (1980), Memorias, Tegucigalpa, Editorial Universitaria, $1^{a}$ edición. (2000), Páginas del ayer, Tegucigalpa, Secretaría de Cultura, 
Artes y Deportes, Colección Biblioteca Básica de Cultura Hondureña, $N^{\circ} 16,2^{a}$ edición.

(2005), Todos los cuentos, Tegucigalpa, Secretaría de Cultura, Artes y Deportes, Edición de José Antonio Funes, $1^{\text {a }}$ edición.

"Himno a Guttenberg", En: Revista de la Universidad, Tegucigalpa, Tomo II, N 9, 15 de septiembre de 1910, pp. 609610.

VEGA JIMÉNEZ, Patricia, (2004), Una aproximación a la historia de la lectura en Costa Rica (1900-1930), San José de Costa Rica, Universidad de Costa Rica (UCR). 